\section{Canopy Photosynthesis and Time-of-day Application of Supplemental Light}

\author{
Jakob Markvart ${ }^{1}$ and Eva Rosenqvist \\ University of Copenhagen, Faculty of Life Sciences, Department of Agriculture \\ and Ecology, Hoejbakkegaard Allé 9, DK-2630 Taastrup, Denmark
}

\author{
Helle Sørensen \\ University of Copenhagen, Faculty of Sciences, Department of Mathematical \\ Sciences, Universitetsparken 5, DK-2100 Copenhagen East, Denmark
}

\section{Carl-Otto Ottosen}

University of Aarhus, Faculty of Agricultural Sciences, Department of Horticulture, Kirstinebjergvej 10, DK-5792 Aarslev, Denmark

Jesper M. Aaslyng

AgroTech, Institute for Agri Technology and Food Innovation, Hoejbakkegaard Allé 21, DK-2630 Taastrup, Denmark

Additional index words. greenhouse climate, circadian rhythms, gas exchange, supplemental light control strategy, chrysanthemum, energy consumption

\begin{abstract}
There is increasing use of electricity for supplemental lighting in the northern European greenhouse industry. One reason for this may be to secure a high growth rate during low-light periods by an attempt to increase net photosynthesis. We wanted to clarify which period of the day resulted in the best use of a 5-h supplemental light period for photosynthesis and growth. The periods tested were supplemental light during the night, day, morning, and evening. The experiments were carried out in daylight climate chambers measuring canopy gas exchange. The air temperature was $25{ }^{\circ} \mathrm{C}$ and the $\mathrm{CO}_{2}$ level $\approx 900 \mathrm{ppm}$. Vegetative chrysanthemum was used, because this species responds quickly to change in light level. The leaf areas of the plant canopies were nondestructively measured each week during the 4-week experimental period. The fact that the quantum yield of photosynthesis is greater at low than at high light intensities favors the use of supplemental light during the dark period, but growth measured as dry weight of the treated plants at the end of the experiments was not significantly different given identical light integrals of the treatments. However, one experiment indicated that increased time with dark hours during day and night $(24 \mathrm{~h})$ might decrease net photosynthesis. The assimilation per unit leaf area was approximately the same during times of sunlight through a diffusing screen at $100 \mu \mathrm{mol} \cdot \mathrm{m}^{-2} \cdot \mathrm{s}^{-1}$ of photosynthetic photon flux $(P P F)$ as during times of supplemental (direct) light application at $P P F$ of $200 \mu \mathrm{mol} \cdot \mathrm{m}^{-2} \cdot \mathrm{s}^{-1} \mathrm{by} \mathrm{high-}$ pressure sodium lamps. We conclude that during the winter and periods of low light intensities, the daily carbon gain does not depend on the time of supplemental light application, but is linked to the total light integral. However, extended time with dark hours during day and night $(24 \mathrm{~h})$ might be a disadvantage because of longer periods with dark respiration and subsequent loss of carbon. Our results indicate that during times of low light conditions, it is not necessary to include factors such as the timing of supplemental lighting application to achieve higher net photosynthesis in climate control strategies.
\end{abstract}

Received for publication 12 Dec. 2008. Accepted for publication 23 Apr. 2009.

We thank the Directorate for Food, Fisheries and Agri Business (DFFE) and 'Danske Prydplanter' for financial support.

Special thanks go to Dvoralai Wulfsohn for her help concerning sampling and CLA estimation, Jakob Skov Pedersen for his help with technical matters about the day-light gas-exchange chambers, Majbrit Dela Cruz for helping with the plant measurements, Janni B. Lund for her advice on how to improve the experimental setup, and Brian Grout and Lawrence White for suggestions on how to improve the manuscript.

${ }^{1}$ To whom reprint request should be addressed; e-mail markvart@life.ku.dk.
(Gartnerirådgivningen/AgroTech, 2008). Supplemental growth light is important for plant production during the darkest period of the year, but knowledge of its optimal use for plant production is lacking. Present greenhouse installations typically have limited supplemental light control options with a fixed intensity, so the main question is when to use supplemental light.

As a result of the increasing cost of electricity, one option is to use the supplementary light during periods of low electricity price, because, for many growers in Denmark and other places, it varies on an hourly basis. Correct matching of the plant circadian clock with the environmental period does influence the net photosynthesis positively (Dodd et al., 2005; Hotta et al., 2007). However, supplemental light during the night period might reset the circadian rhythms of the crop, and it is not known to what degree night interruption might affect the net canopy carbon gain and subsequent plant growth.

Extending the length of the day to obtain a certain light integral might result in greater net photosynthesis as a result of a reduction in dark respiration (Nemali and van Iersel, 2004; Xu et al., 2004). However, supplemental light is mainly used during the dark period of the year where light conditions during the day and nights are low and the increase in photosynthesis with increasing light intensity is more or less linear. The light level at which linearity ends depends on the plant species and the capacity of the plant for light acclimation of photosynthesis to the prevailing light level (Rosenqvist, 2001). At light levels below a photosynthetic photon flux $(P P F)$ of $200 \mu \mathrm{mol} \cdot \mathrm{m}^{-2} \cdot \mathrm{s}^{-1}$, the leaf assimilation of chrysanthemum can be considered as responding close to linearly to irradiance levels. Supplemental light levels differ but are often lower than $200 \mu \mathrm{mol} \cdot \mathrm{m}^{-2} \cdot \mathrm{s}^{-1}$ at the canopy level. Pot plants grown at a typical production facility during winter in Denmark will be exposed to irradiance levels below $500 \mu \mathrm{mol} \cdot \mathrm{m}^{-2} \cdot \mathrm{s}^{-1}$.

The aim of the study was to evaluate the efficiency of photosynthesis of an intact crop on a short-term basis and its growth during a 4-week period with supplementary light at different periods of the day at identical light integrals. Short-term evaluation time of the four supplemental light strategies was aimed to get the most value for the money out of the installation. The results are evaluated for their importance in typical greenhouse production practice. energy. The economic aspect of reducing energy for heating has already induced growers to use dynamic temperature control to a greater extent. Danish pot-plant producers reduced their use of energy for heating per square meter greenhouses by $23 \%$ from 2000 to 2006, whereas their use of electricity per square meter greenhouses, mainly used as supplemental growth light, increased by $30 \%$ in the same period (Møllenberg, 2003, 2007). It has been reported that supplemental growth light has increased in Denmark although the overall energy use per unit has decreased

\section{Materials and Methods}

Facilities. Five semiclosed-canopy daylight gas-exchange chambers (chambers), each with a volume of $1.3 \mathrm{~m}^{3}$ (Jensen et al., 2006), were used for the two experiments. Each chamber was equipped with a range of sensors (Jensen et al., 2006) and in this study, the combined relative humidity $(\mathrm{RH})$ and a temperature sensor (HygroClip S; Rotronic, Bassersdorf, Switzerland) were used. A mass 
flow controller (5850TR; Brooks Instrument, Hatfield, PA) enabled controlled injections of carbon dioxide $\left(\mathrm{CO}_{2}\right)$ and measurements of the injected $\mathrm{CO}_{2}$. The actual $\mathrm{CO}_{2}$ concentrations were measured continuously in all chambers using Vaisala CARBOCAP ${ }^{\circledR}$ Carbon Dioxide Probes (GMP343; Vaisala, Helsinki, Finland). Two high-pressure sodium lamps (SON-T, Green Power; Philips, Bruxelles, Belgium) were placed $1 \mathrm{~m}$ above each chamber supplementing natural light with a $P P F$ of $160 \mu \mathrm{mol} \cdot \mathrm{m}^{-2} \cdot \mathrm{s}^{-1}$ at the plant level. Incandescent light bulbs $(100 \mathrm{~W})$ were used for long-day treatment.

A light-diffusion screen (XLS 10 FIREBREAK; AB Ludvig Svensson, Kinna, Sweden) was placed above the chambers to reduce the difference in sunlight distribution between the chambers caused by shade from the greenhouse construction. A sunlight calibrated Apogee line quantum sensor (LQS506; Apogee Instruments, Inc., Logan, UT) and a LI-COR quantum sensor (LI-190; LI-COR, Lincoln, NE) were fixed above the canopy in each chamber and used to measure $P P F$ $\left(\mu \mathrm{mol} \cdot \mathrm{m}^{-2} \cdot \mathrm{s}^{-1}\right)$. Climate measurements from each chamber were logged every minute.

Climate and plant material. The temperature set point was $25^{\circ} \mathrm{C}$. $\mathrm{CO}_{2}$ was controlled to $900 \mathrm{ppm}$ by $\mathrm{CO}_{2}$ injections and by ventilation when the $\mathrm{CO}_{2}$ concentration reached $1000 \mathrm{ppm}$ as a result of respiration. Cuttings of Chrysanthemum $\times$ morifolium Ramat 'Midnight time' delivered from a commercial production were grown in Grodan ${ }^{\circledR}$ blocks (Grodan ${ }^{\circledR}$ Delta 6,5 20/15, Grodan BV, Roermond, The Netherlands). At a size of approximately four leaves (greater than $2 \mathrm{~cm}$ ), after $\approx 4$ weeks of propagation, the plants were moved to the chambers for acclimation for 1 week. The experiments started 18 Jan. 2008 and ended 14 Feb. 2008. At the start of the experiments, sunrise-sunset was $0826 \mathrm{HR}$ to $1614 \mathrm{HR}$ and at the end $0738 \mathrm{HR}$ to $1711 \mathrm{HR}$. In addition to the sunlight during the daytime, long-day treatment light was applied using incandescent light bulbs from $0500 \mathrm{HR}$ to 2000 HR during propagation, acclimation, and during the experiments to avoid flower initiation.

During the acclimation and the experiments, supplemental growth light was applied in periods of $5 \mathrm{~h}$ accounting for $\approx 58 \%$ of the total $P P F$ on average. During the acclimation, the 5-h supplemental light was placed from $1000 \mathrm{HR}$ to $1500 \mathrm{HR}$.

Plants were kept moist at all times and were watered simultaneously from a common tank with a full nutrient solution (Hornum 5-1-4 PLUS Mg \& S; P. Brøste A/S, Lyngby, Denmark) controlled with nitric acid at $\mathrm{pH}$ of 5.8 and electrical conductivity (EC) of $2.0 \mu \mathrm{S}$ using an ebb and flood system in each of the chambers. We measured $\mathrm{pH}$ and EC each week using a handheld combined $\mathrm{pH}, \mathrm{EC}$, and temperature measuring device (Mesur; Senmatic A/S, DGT-Volmatic, Søndersø, Denmark).

Height was measured for 260 propagated plants before the start of the experiments and lowest and tallest plants were discarded, leaving 176 plants of similar size. These were distributed into homogeneous groups, each having similar distributions of sizes based on plant height by using a smooth fractionation sampling method (Wulfsohn et al., 2009).

Each plant group consisted of 32 plants and another 16 plants representative and equivalent in height to the other plant groups were selected for the destructive start measurements (S0). During acclimation, these plant groups were separated and an equal number of plants from each group were placed in each of the chambers (one to five). After acclimation, destructive measurements were performed on S0 and plants belonging to the same group were put back together and placed in the chambers for each of their separate treatments.

Treatments. We tested four treatments differing in position of the periods with supplemental light. In experiment $\mathrm{T}_{\text {Keep }}$, each plant group got the same treatment through the whole experiment but plants and treatments were rotated among chambers $1,2,3$, and 4 after each experimental week to minimize the influence of possible chamber effect on the final results. In experiment $\mathrm{T}_{\text {Change, }}$, the plants remained in chamber 5 with the time of supplemental light application changing from week to week (Table 1). Each individual treatment will be referred to as $\mathrm{T}$ for treatment of experiment $\mathrm{T}_{\text {Keep }}$ and $\mathrm{TCh}$ for treatment of experiment $\mathrm{T}_{\text {Change }}$ followed by the time of the day of the supplemental light periods (24-h clock).

After 1 week of acclimation of the plants to the chamber conditions, the two experiments lasted 4 weeks and were run simultaneously. Experimental days were defined as $24 \mathrm{~h}$ starting at $1000 \mathrm{HR}$. Each experimental week consisted of 6 experimental days and $1 \mathrm{~d}$ for measurements of plant growth, rotation of plants, and treatments between the chambers, and so on. Plant growth measurements were performed on Days $0,7,14,21$, and 28. During these days, none of the plant groups received supplemental light except from the long-day treatment by the light bulb.

Biometrical analysis. For biometrical measurements, 16 plants from each plant group were selected using systematic uniform random (SUR) sampling with a period of two and random start (providing a sampling fraction of half of the canopy) from a "smooth" (monotonically increasing and then decreasing) arrangement of plants by height (Gundersen, 2002; Wulfsohn et al., 2009). Plant heights were measured, the total numbers of leaves and shoots on the main stem counted, and the number of plants with flower initiation registered. The total canopy leaf area (CLA) for each treatment was estimated using a stereological sampling procedure involving sampling of leaves and point-counting of leaf areas. The number of plants and leaves and the size of the point grid used depended on the plant size (systematic sampling provides sample sizes proportional to plant size). Leaves for point counting were selected as being the SUR sampled leaf on the main stem including leaves on any adjoining shoot present.

The total canopy surface area (CLA) was estimated using the formula:

$$
C L A \approx \frac{a_{p} P}{f_{p} f_{l}},
$$

where $a_{p}$ is the area per point on the point grid used, $P$ is the total number of points of the randomly placed square point counting grid on the final sample of leaves, $f_{p}$ is the fraction of SUR sampled plants, and $f_{l}$ is the fraction of SUR sampled leaves. The SEM of the CLA estimator was estimated from the data using Eq. 14 in Wulfsohn et al. (2009) plus an estimated $4 \%$ contributing to the SEM resulting from sampling of plants based on Wulfsohn et al. (2009).

At Days 0 and 7, 16 plants $\left(f_{p}=\right.$ half of the canopy) and every fifth leaf ( $f_{l}=$ one-fifth of sampled plant surface areas and therefore one-tenth of the canopy) were SUR-sampled and a point-grid of $a_{p}=2.24 \mathrm{~cm}^{2}$ per point was used. At Days 14, 21, and 28, eight plants ( $f_{p}=$ one-fourth of the canopy) and every third leaf $\left(f_{l}=\right.$ one-third of sampled plant surface areas and therefore one-twelfth of the canopy) were SUR-sampled and a point-grid of $a_{p}=3.43 \mathrm{~cm}^{2}$ per point was used.

Plant heights (millimeters) were measured from the base to the meristem. We counted the number of leaves longer than $2.0 \mathrm{~cm}$ on the main stems as a measure of the nodes on each plant.

Lateral shoots with at least two leaves greater than $2.0 \mathrm{~cm}$ were counted as a measure of plant volume. Both lateral shoots and flower initiation, which occurred despite

Table 1. The experimental plan of the rotation of the 5-h supplemental light treatment periods between the chambers (chamber 1-4) for experiment $\mathrm{T}_{\mathrm{Keep}}$ and the placement of 5-h supplemental light treatment periods during experiment $\mathrm{T}_{\text {Change. }}{ }^{\mathrm{z}}$

\begin{tabular}{|c|c|c|c|c|c|c|}
\hline Expt. & & & & & & $\mathrm{T}_{\text {Change }}$ \\
\hline Chamber & & 1 & 2 & 3 & 4 & \\
\hline $\begin{array}{l}\text { Time } \\
\text { Week } 1\end{array}$ & $\begin{array}{l}\text { Supplemental light } \\
\text { treatment period }\end{array}$ & $10-15$ & $15-20$ & 23-04 & $05-10$ & $10-15$ \\
\hline $\begin{array}{l}\text { Week } 2 \\
\text { Week } 3 \\
\text { Week } 4\end{array}$ & & $\begin{array}{l}05-10 \\
23-04 \\
15-20\end{array}$ & $\begin{array}{l}10-15 \\
05-10 \\
23-04\end{array}$ & $\begin{array}{l}15-20 \\
10-15 \\
05-10\end{array}$ & $\begin{array}{l}23-04 \\
15-20 \\
10-15\end{array}$ & $\begin{array}{l}23-04 \\
15-20 \\
05-10\end{array}$ \\
\hline
\end{tabular}

${ }^{z}$ The times listed are hours of the day with supplemental light (24-h clock). Supplemental light treatment periods and plants follow each other in experiment $T_{\text {Keep }}$. In experiment $T_{\text {Change }}$, the supplemental light treatment periods are changing from week to week on the same group of plants in chamber 5. Experimental period: 17 Jan. 2008 to 14 Feb. 2008. 
the long-day treatment, were counted on the same sample of plants as for the plant height and leaves on the main stem (nodes). Flower initiation was registered when the plants developed linear and entire (not roundtoothed) leaves at the apex.

Fresh weight of the aboveground plant material in proportion of leaves and stems of individual plants was measured on S0 plants at Day 0 and on 16 SUR-sampled plants of treatment T10-15, T15-20, T23-04, and T0510 from experiment $\mathrm{T}_{\text {Keep }}$ and 16 SURsampled plants of TCh at Day 28. Dry weight (DW) of leaves and stems was measured after drying for $48 \mathrm{~h}$ at $85^{\circ} \mathrm{C}$.

Calculation of net canopy $\mathrm{CO}_{2}$ exchange. The rate of net canopy $\mathrm{CO}_{2}$ exchange, $\mathrm{A}$ $\left(\mu \mathrm{mol} \cdot \mathrm{m}^{-2} \cdot \mathrm{s}^{-1}\right)$, was estimated by calculating the $\mathrm{CO}_{2}$ balance of the chamber (Jensen et al., 2006). During the day, the chamber operates as a closed system and during the night as semiclosed.

Instead of measuring the withdrawal of $\mathrm{CO}_{2}$ from the system during ventilation at night (air renewal), we based the calculation on the difference in the $\mathrm{CO}_{2}$ concentrations in the chamber before and after ventilation.

To eliminate the effect of signal noise, data for $\mathrm{CO}_{2}$ concentration, air temperature, air pressure, and $\mathrm{RH}$ were transformed into smoother data using running averages, so each time point was based on the average of the actual data point and data points $7 \mathrm{~min}$ before and after the data point value. The same procedure was used for the data of minute-based $\mathrm{CO}_{2}$ injections controlled and measured by the mass flow controllers. During $15 \mathrm{~min}$ (= the running average intervals), three to five $\mathrm{CO}_{2}$ injections occurred during periods with supplemental light. The rate of net canopy $\mathrm{CO}_{2}$ exchange was based on these running average values. Because we wanted to compare the net canopy $\mathrm{CO}_{2}$ exchange of plants of different ages/sizes, we based the $\mathrm{CO}_{2}$ exchange on total CLA estimated as described previously. A linear correlation of the estimated CLA was made between the measuring days. The correlation was minutebased for each plant group. The net canopy $\mathrm{CO}_{2}$ exchange of plants in the chambers was divided by the CLA of the actual plant group. After the calculation of the canopy assimilation per CLA (A/CLA), another running average was made based on the average of the actual data point, data points $7 \mathrm{~min}$ before and after the data point value. Running averages were also made of the measurements of $P P F$ based on 15 values.

Calculations and statistical methods. All assimilation data during system interruption or failure were deleted before calculations. The minute-based values were used to calculate the average net canopy $\mathrm{CO}_{2}$ exchange per total CLA (average A/CLA). Average values were calculated in steps of $10 \mathrm{~min}$ and then in 1-h and 24-h intervals. The 24-h intervals (D) were only included if the data set was complete for the 24-h intervals.

Overall means of $\mathrm{CO}_{2}$, air temperature, $\mathrm{RH}$, and $P P F$ for the treatments (T10-15, T15-20, T23-04, T05-10, and TCh) during the 4-week duration (four values per treatment) of the experiments were found and analyzed using a one-way analysis of variance (ANOVA) with treatment as the explanatory variable. The climate outcomes were also analyzed for experiment $\mathrm{T}_{\text {keep }}$ alone with a two-way ANOVA on daily averages with treatment $(\mathrm{T})$ and chamber $(\mathrm{C})$ as explanatory variables. The general linear models procedure (PROC GLM) of SAS was used for the computation (SAS Institute, Cary, NC). In experiment $\mathrm{T}_{\text {Keep }}$, the treatment effects $(\mathrm{T})$ and chamber effects $(\mathrm{C})$ on the daily A/CLA were analyzed with the mixed model procedure (PROC MIXED) of SAS. Daily average values of $P P F, \mathrm{CO}_{2}$ concentration, and air temperature were included in the analysis as covariates and excluded stepwise where no significant effect appeared. Experimental days (D) were included as random effects.

The daily A/CLA values from experiment $\mathrm{T}_{\text {Change }}$ were analyzed with a general linear model with the effect of treatment (TCh) and the previously mentioned climate covariates. Also, the climate outcomes of experiment $\mathrm{T}_{\text {Change }}$ were analyzed with a general linear model with the effect of treatment (TCh).

The biometrical growth measures were analyzed with a one-way ANOVA with treatment $(\mathrm{T})$ as the explanatory variable for each week separately based on data from 16 plants from each treatment group.

For the economical aspect of using supplemental light in the different periods, hourly electricity prices for E Denmark were collected from http://www.nordpool.com between 18 Jan. and 14 Feb. 2008 (same period as the experiment).

\section{Results}

Climate. The average $\mathrm{CO}_{2}$ concentration per week for chambers $1,2,3,4$, and 5 was: $944 / 937,823 / 812,840 / 829,844 / 831$, and 977/967, respectively (highest/lowest weekly average, ppm), daily varying $\approx 100 \mathrm{ppm}$. However, because the plants were rotated between the chambers in experiment $\mathrm{T}_{\mathrm{Keep}}$, the average $\mathrm{CO}_{2}$ concentration per week was not significantly different for plant groups/ treatments in this experiment. The climate of experiment $\mathrm{T}_{\text {Change }}$ differed with regard to the weekly means of the daily $\mathrm{CO}_{2}$ concentration being significantly higher $(P=$ 0.0134 ) with $\approx 12 \%$ compared with treatments of $\mathrm{T}_{\text {Keep }}$ (Fig. 1A). The air temperature was maintained stable at $25{ }^{\circ} \mathrm{C}$ with no significant differences between treatments $(P=0.9405)$ (Fig. 1B). RH varied between $50 \%$ and $70 \%$ at all times and resulted in no statistical differences among the $\mathrm{RH}$ of the treatments $(P=0.9936)$ (Fig. 1C). Likewise, no significant differences of the weekly means of the daily (24-h) average $P P F$ were found among the treatments $(P=0.6819)$ (Fig. 1D).

The highest light intensities were observed during treatments with supplemental light during the day (T10-15 and TCh10-15).

Biometrical data. Plant height measured at the beginning of each week is shown in Figure 2A. There were no statistical differ-
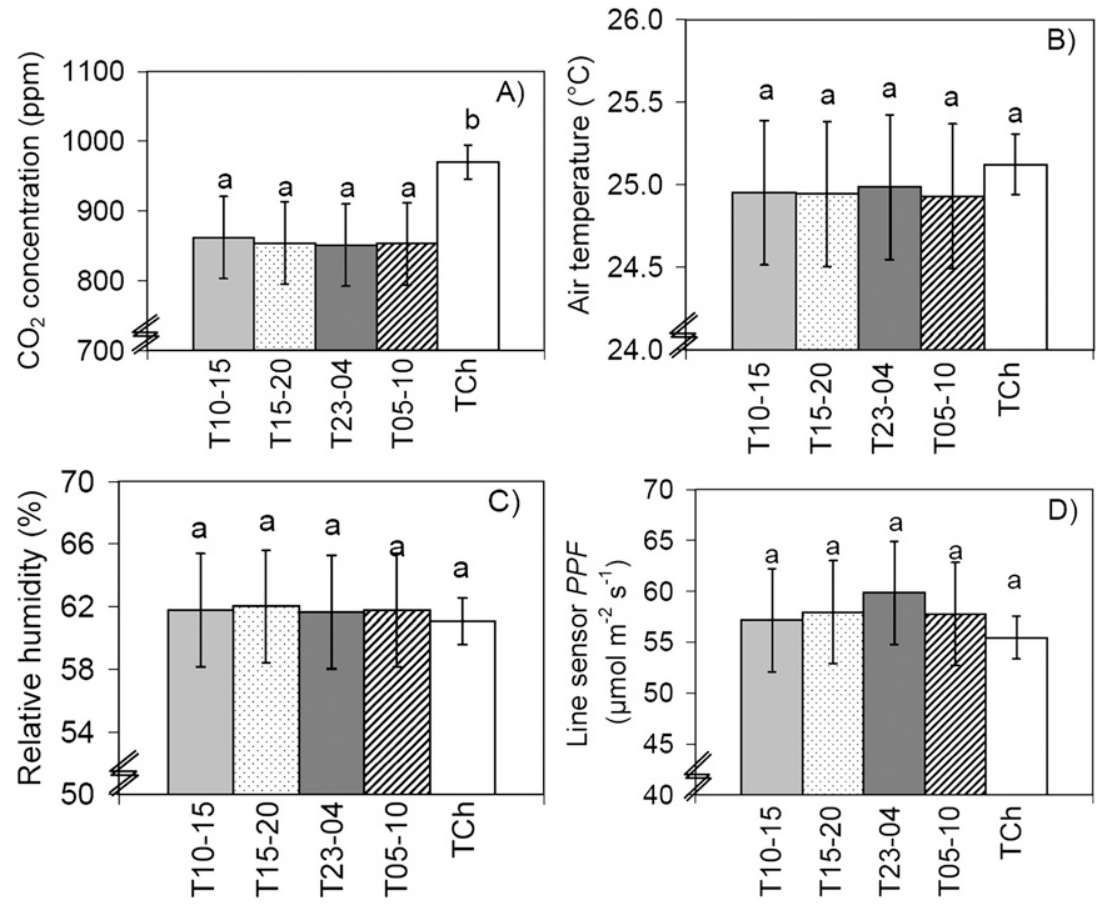

Fig. 1. Means of the daily averages of climatic data in chambers for the different treatments during the 4week duration of the experiments are shown for $(\mathbf{A}) \mathrm{CO}_{2}$ concentration, $(\mathbf{B})$ air temperature, $(\mathbf{C})$ relative humidity and (D) photosynthetic photon flux $(P P F)$ measured by the Apogee line sensor. The bars indicate $95 \%$ confidence limits of the estimates of the weekly means (four values for each treatment). Different letters indicate significant differences between treatments. 

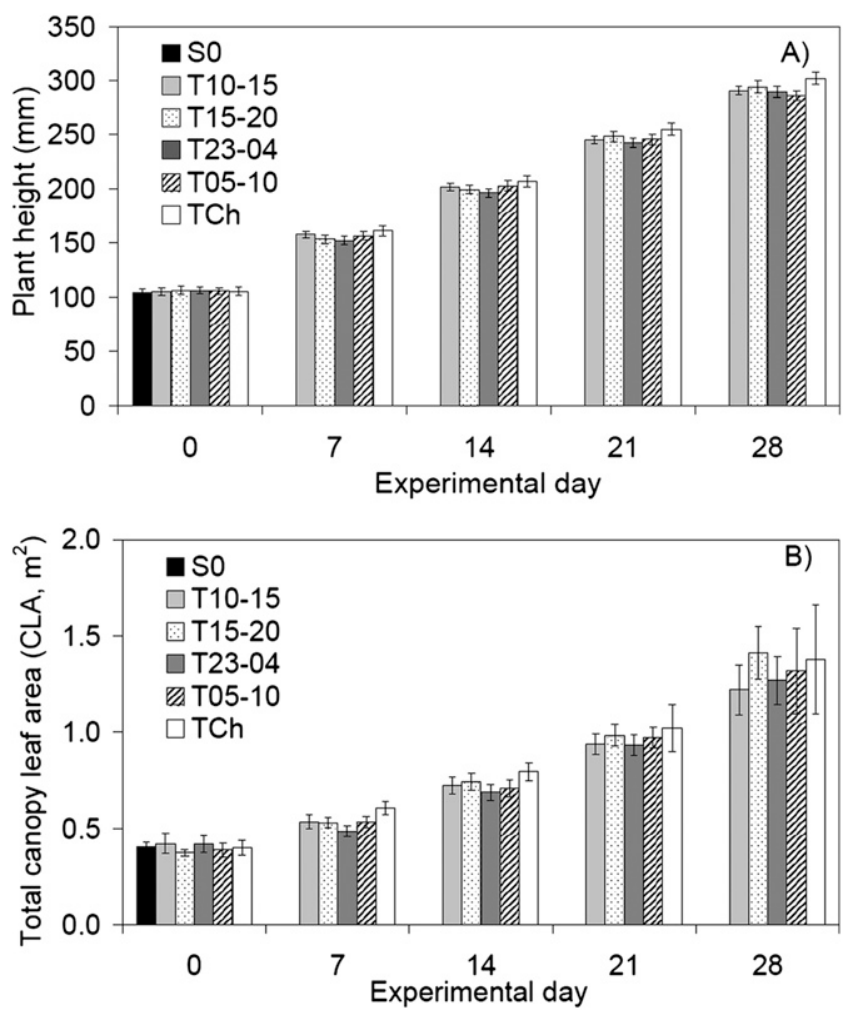

Fig. 2. (A) Plant height over the duration of the experiments. The bars represent \pm SEM based on measurements of 16 plants. For each measuring day, no significant differences were found. Linearity of the average plant height was found throughout the experimental period. (B) The estimated total canopy leaf area (CLA) of the 32 plants for each plant group during the experiments. The bars are \pm the estimated SEM of the surface area estimator predicted according to Wulfsohn et al. (2009) Eq. 14, for each treatment (i.e., one canopy only, without replication) on Days 0, 7, 14, 21, and 28.

ences with regard to plant height among the treatments at each of the measuring days. The lowest $P$ value was 0.23 at Day 28. The growth of the plants (plant height) was found to be linear throughout the experimental period.

No treatment effects on total plant CLAs were observed (Fig. 2B). The CLA estimations resulted in an average leaf area index (LAI) of 1.0 at Day 0 and at 3.1 at Day 28.

There were no significant differences with regard to the number of leaves on the main stem (nodes) per 16 SUR-sampled plants between the treatments (the lowest $P$ value was 0.15 at Day 14). Flower initiation was observed at the end of the second week. At the end of the third week, approximately half of the plants of all treatments were flowerinitiated (data not shown). Most plants had initiated flowering at the end of the experiments influencing the number of lateral shoots and number of nodes of these plants. The average number of new nodes per week was slightly less between Day 21 and Day 28 than for the previous weeks (data not shown). This decline corresponds to an increase in the number of lateral shoots. At Day 28, the number of lateral shoots were greatest in treatment T15-20 (data not shown), similar to the insignificant $\approx 5 \%$ higher leaf area estimation of T15-20 (Fig. 2B).

The total fresh weight measured on samples of plants from each treatment at the end of the experiment corresponded relatively to the total dry weight of the same samples. Comparing the total dry matter of plants from the treatments included in experiment $\mathrm{T}_{\mathrm{Keep}}$, no significant differences were found $(P=$ $0.80)$. The dry matter of plants from $\mathrm{T}_{\text {Change }}$ was not significantly different from that of plant groups of experiment $\mathrm{T}_{\text {Keep }}(P=0.49)$. Figure 3 shows the average dry weights of stems and leaves with no significant differences found among the treatments.

Net canopy $\mathrm{CO}_{2}$ exchange. Control of the data modulation (smoothing of data) was done by comparing curves and sums and averages in several time intervals before and after the calculations. Data tested within the different time intervals showed no significant differences (data not shown), i.e., the statistical analysis of treatment effects is unaffected, only the visualization of the data in figures. The smoothing of data by using the running average of the gas exchange data and the measured $P P F$ resulted in minor fluctuations (less noise). The modulation made it also visually easier to compare the measured $P P F$ with the actual A/CLA and the quick response of the system and of the plants to changing light levels is clearly seen (Fig. 4).

When supplemental light was used, the A/ CLA was not as high as during sunlight at the same light intensity measured irrespective of treatment and chamber.

Analysis of assimilation/canopy leaf area from experiment $T_{\text {Change. }}$ In the analysis of

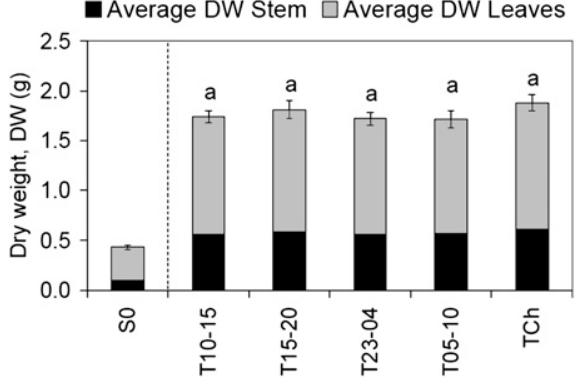

Fig. 3. Average dry weight per plant for all treatments at the end of Week 4 in proportion of leaves and stems. S0 represents the starting fresh weight at Day 0 . The bars represent \pm SEM based on measurements of 16 plants. Letters indicate no significant differences.

experiment $\mathrm{T}_{\text {Change, }}$, we included the effect of the four treatments $\left(\mathrm{T}_{\mathrm{Ch}}\right)$ and the average $P P F$ per day (as a covariate) in a model of factors influencing the A/CLA. Other climate parameters were included but had no significant effect and were hence excluded stepwise. This resulted in a significant effect of the average $P P F$ per day $(\mathrm{F}=94.04, P<$ $0.0001)$ and a significant effect of treatments (F $=8.18, P=0.0026)$.

In pairwise comparison of the treatments, TCh10-15 had a significantly lower estimated A/CLA per day than the other treatments (the largest $P$ value was 0.0058 ). There was no significant differences between experimental weeks with regard to the average $P P F$ per day $(\mathrm{F}=0.46, P=0.72)$ (Fig. 5).

No significance was found between the average $P P F$ per day because of relatively large natural variation in the $P P F$ (sunlight) between the days.

Analysis of assimilation/canopy leaf area from experiment $T_{\text {Keep }}$. Using the mixed procedure in the analysis of experiment $T_{\text {Keep }}$, we included experimental days (D) as a random effect and treatment $(\mathrm{T})$ and chamber effect (C) and interaction between them $(\mathrm{T} \times \mathrm{C})$ as main effects and $\mathrm{CO}_{2}$ concentration and $P P F$ per day as covariates in the model. We found no significant effect of the $\mathrm{CO}_{2}$ concentration $(\mathrm{F}=0.42, P=0.52)$ but a significant effect of the average $P P F$ per day $(\mathrm{F}=90.38, P<0.0001)$ on the A/CLA per day. This model showed a significant interaction between treatment and chamber $(\mathrm{T} \times \mathrm{C})$ $(\mathrm{F}=2.60, P=0.025)$.

When we excluded the $\mathrm{CO}_{2}$ concentration as a covariate in the model, the effect of $\mathrm{T} \times \mathrm{C}$ remained significant $(\mathrm{F}=2.66, P=0.023)$. The order of the greatest A/CLA per day differs depending on the combination of chamber and treatment (Fig. 6).

The A/CLA values were generally higher for chamber 2 than for the other chambers. However, there is no general effect of treatment. In the model with additive effects of $\mathrm{T}$, $\mathrm{C}$, experimental week $(\mathrm{W})$, and $P P F$, then there was no significant effect of $\mathrm{T}(\mathrm{F}=2.07$, $P=0.12)$ and $\mathrm{W}(\mathrm{F}=2.29, P=0.13)$, whereas $\mathrm{C}(\mathrm{F}=38.48, P<0.0001)$ and $P P F(\mathrm{~F}=$ 101.53, $P<0.0001)$ were significant. 


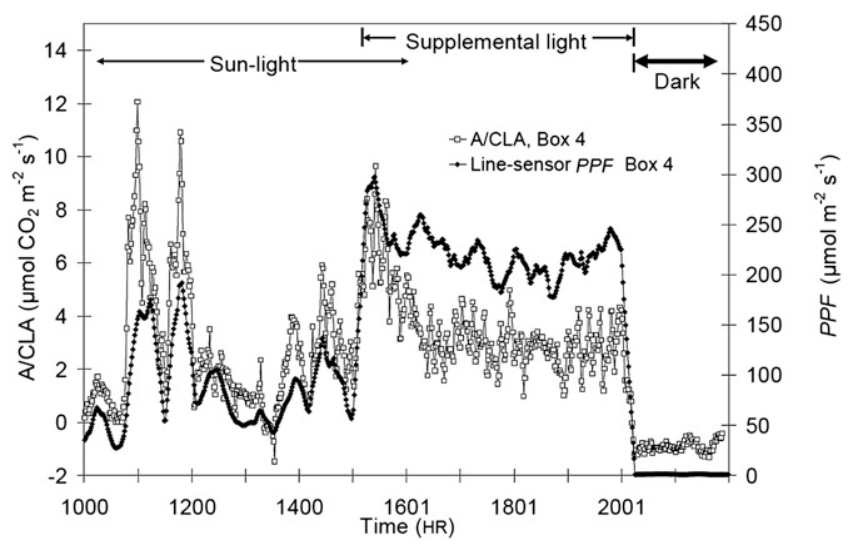

Fig. 4. The assimilation per canopy leaf area (A/CLA, open squares, left y-axis) and the photosynthetic photon flux $(P P F)$ measured with the Apogee line sensor $(P P F$, filled diamonds, right $\mathrm{y}$-axis) per minute. Data are from experimental Day 20, chamber 4.
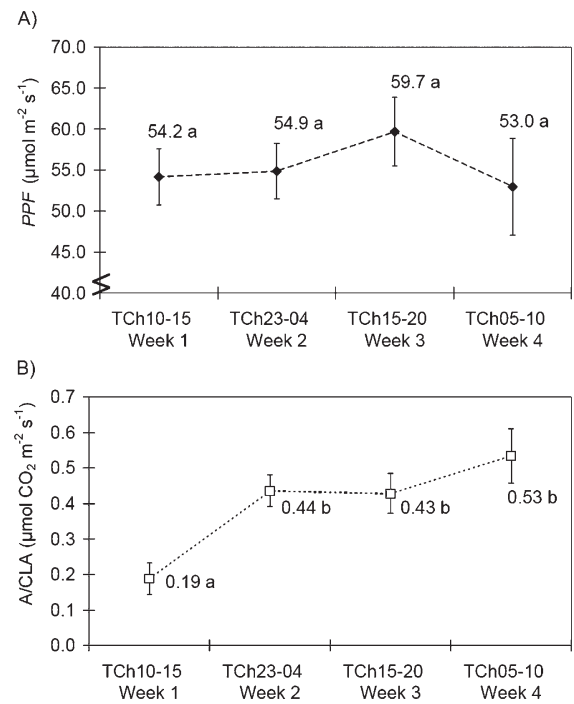

Fig. 5. (A) Estimates of daily average photosynthetic photon flux ( $P P F$, filled diamonds) and (B) estimates of daily average assimilation per canopy leaf-area (A/CLA, open squares) for the different weeks during experiment $\mathrm{T}_{\text {Change }}$ The bars indicate $95 \%$ confidence limits of the estimates.

Economical aspects. From 18 Jan. to 14 Feb. 2008 (4 weeks), the difference in the hourly electricity prize varied between 0 and 120 USD/MWh between extremes resulting in an average difference of 47 USD/MWh per day. The overall average prize was 65 USD/ MWh and the highest prices were observed in the daytime between $0700 \mathrm{HR}$ and $2100 \mathrm{HR}$. Average cost for applying light in the periods tested in this study with these prices for T0510, T10-15, T15-20, and T23-04 would have been $68,70,78$, and 52 USD/MWh, respectively. The most expensive period was more than $66 \%$ more expensive than the cheapest period during the time of the experiment.

\section{Discussion}

We found no statistically significant differences among the average air temperatures, $\mathrm{RH}$, and $P P F$ for the different treatments and the main course of variability in the climates of the chambers was the variation in natural light.

The average $\mathrm{CO}_{2}$ concentrations of the chambers differed marginally because of differences in calibration of the $\mathrm{CO}_{2}$ sensors. However, regrouping of the plants during the acclimation week ensured that the plant groups were subjected to equal effect of each of the chambers before the start of the experiments. Moreover, the treatments and corresponding plant groups in experiment $\mathrm{T}_{\text {Keep }}$ involving chambers $1,2,3$, and 4 were rotated among the chambers diminishing ences. The plants used in experiment $\mathrm{T}_{\text {Change, }}$, which only involved chamber 5 , were grown in an overall higher $\mathrm{CO}_{2}$ concentration.

Estimated A/CLA for experiment $\mathrm{T}_{\text {Change }}$ was generally small because of the $\mathrm{CO}_{2}$ flow controller for inlet of $\mathrm{CO}_{2}$ to chamber 5 leaked a small amount of unmeasured $\mathrm{CO}_{2}$. Thus, the level A/CLA per day is generally underestimated for experiment $\mathrm{T}_{\text {Change }}$ and more accurate for experiment $\mathrm{T}_{\text {Keep }}$. The leak did not influence the result except for underestimation of A/CLA for all treatleak was stable throughout the experiment only influencing experiment $\mathrm{T}_{\text {Change }}$ (chamber 5). Therefore, the treatments across experiments $\mathrm{T}_{\text {Change }}$ and $\mathrm{T}_{\text {Keep }}$ should not be compared.

Despite the long-day treatment, leaves toothed indicated flower initiation toward the end of the experiments although no buds appeared. Flower initiation and the number of side shoots and consequently the estimated CLA were greatest for the plant group in treatment T15-20. The amount of new leaves and nodes on the main stem declined during the last week of the experiment indicating that the plants were about to reach a plateau of height before their generative growth stage. However, the average plant heights increased with linear growth rates throughout the experimental period and the plant groups of the different treatments were visually alike (Fig. 2). Thus, we assume that the plants did the effects of the $\mathrm{CO}_{2}$ and chamber differments of experiment $\mathrm{T}_{\text {Change}}$, because the that were linear, entire, and not round-
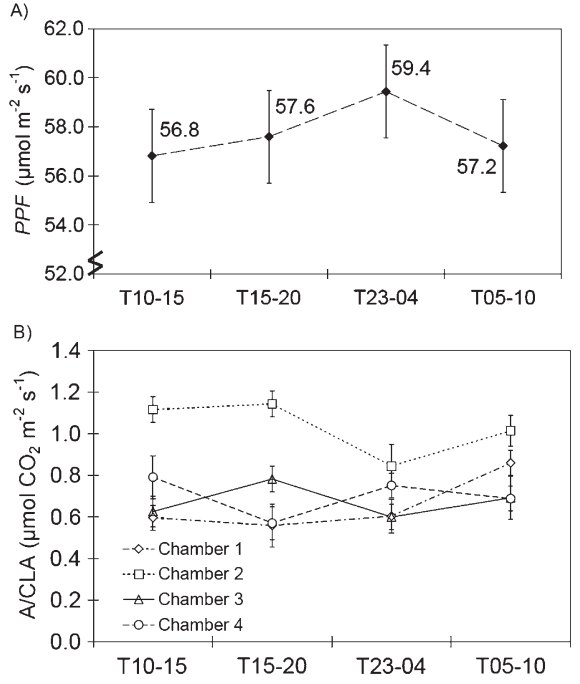

Fig. 6. (A) The estimates of daily average photosynthetic photon f lux ( $P P F$, filled diamonds) for the treatments during experiment $\mathrm{T}_{\text {Keep. }}$. (B) The estimates of daily average assimilation per canopy leaf area (A/CLA, open symbols) for the different chambers and treatments during experiment $\mathrm{T}_{\text {Keep }}$. The daily average A/CLA showed interactions between the treatments and chambers $(\mathrm{T} \times \mathrm{Ch}$ effect). The bars indicate $95 \%$ confidence limits of the estimates.

not change their photosynthetic behavior during the time of the experiments.

There were no significant differences between the dry weights of plants from treatments in experiment $T_{\text {Keep }}$. The fact that the dry matter of the plant group of TCh is the highest of all plant groups can be explained by a generally higher $\mathrm{CO}_{2}$ concentration in chamber 5 . We can conclude that there were no major differences in plant growth or climate among the treatments, indicating that the efficiency of supplemental light is independent of what time of the day it is used in chrysanthemum.

From the analysis of the $\mathrm{T}_{\text {Change, }}$ treatments TCh23-04 (Week 2), TCh15-20 (Week 3 ), and TCh05-10 (Week 4) show greater estimated A/CLA per day than treatment TCh10-15 (Week 1). The model includes the $P P F$ per day as a covariate. The distance from the canopy top leaf level to the supplemental light source decreased by $5 \mathrm{~cm}$ each week (Fig. 2A). This was measured to equal a difference in $P P F$ of $\approx 30 \mu \mathrm{mol} \cdot \mathrm{m}^{-2} \cdot \mathrm{s}^{-1}$ from the start to the end. $P P F$ was not measured at the canopy level, but the sensor was fixed in the chamber just above the final canopy height. This is a part of the explanation of lower A/CLA, because the longer distance to the light source decreases available light for photosynthesis. However, because the estimates are weighted depending on the $P P F$, and the $P P F$ levels of the different weeks are alike (Fig. 5A), the $P P F$ levels cannot explain the lower A/CLA estimate for TCh10-15 (Week 1) (Fig. 5B).

The increase in the CLA estimation of TCh between Days 0 and 7 was insignificantly greater than the following weeks (Fig. 
2B) and therefore the CLA estimation is not the explanation for the low A/CLA during experimental Week 1 . We assume that acclimating the plants to the humidity and air movement in chambers for 1 week is sufficient based on experience with the species, but we do not know if the plants were strained during treatment TCh10-15 (Week 1), because of a too short acclimation period. However, the A/CLA estimated might be explained to some extent by a changed assimilation depending on the plant age. Nemali and van Iersel (2004) found a linear increase in dry weight per day of wax begonia (Begonia semperflorens-cultorum Hort.) with increasing daily light integral (DLI), but plants grown at low DLI (5.3 or 9.5 $\left.\mathrm{mol} \cdot \mathrm{m}^{-2} \cdot \mathrm{d}^{-1}\right)$ respired more carbohydrates than were fixed in photosynthesis during the early growth period. With a similar low DLI in our experiments $\left(\approx 5.2 \mathrm{~mol} \cdot \mathrm{m}^{-2} \cdot \mathrm{d}^{-1}\right)$, the proportion of respired carbohydrates to what was fixed in photosynthesis might be larger during the initial week opposed to later weeks.

The LAI increases with plant age and because the supplemental light was not diffused, it did not reach the lower leaves during the last weeks. Therefore, the amount of diffused sunlight and the CLA estimation are crucial for the estimation of A/CLA. A more accurate CLA estimation requires even more time and does not affect the principles in results. Furthermore, how the more or less diffused light is measured by the sensors does not reflect how light is sensed by the plant at different ages and LAIs. The importance of the degree of diffuseness of light for the $P P F$ measurements in relation to measurements of $\mathrm{A} / \mathrm{CLA}$ is illustrated in Figure 4.

A light diffusion screen was initially placed above the chambers to reduce the moving shades from the construction of the greenhouse. Light levels below 150 $\mu \mathrm{mol} \cdot \mathrm{m}^{-2} \cdot \mathrm{s}^{-1} P P F$ occur during times of no supplemental light application where the light originates from the sun coming through the diffusing screen (Fig. 4). The A/CLA of the diffused light at $100 \mu \mathrm{mol} \cdot \mathrm{m}^{-2} \cdot \mathrm{s}^{-1} P P F$ seems to equal that of supplemental light at light intensities of $200 \mu \mathrm{mol} \cdot \mathrm{m}^{-2} \cdot \mathrm{s}^{-1} P P F$. Diffused sunlight seems therefore to be far more efficient for whole crop photosynthesis than supplemental light.

Tibbitts et al. (1986) have demonstrated that different photon flux sensors can exhibit measurable differences in response depending on the radiation sources used. To clarify whether the $P P F$ sensors used were less sensitive for the particular wavelengths, we compared the spectral composition of the lamps and the spectral sensitivity of the $P P F$ sensors. This did not explain the fact that the sensor output during supplemental light was relatively high in relation to the relatively low assimilation. The pattern was identical with both the LI-COR and Apogee sensors.

The importance of diffused light on canopy gas exchange measurements has long been recognized (Hollinger et al., 1994;
Norman et al., 1971; Roderick et al., 2001) and one could speculate whether our results only relate to canopies with greater LAI. However, the pattern was also seen with data only from experimental Week 1 with an LAI less than 1.5. Thornley (2002) describes how higher degrees of diffuseness of light theoretically will increase the assimilation. We may have demonstrated this, but our measurements suggest the increase in assimilation is greater than that described by Thornley (2002) comparing $100 \%$ diffused radiation with $75 \%$ of the radiation incident on an exposed horizontal surface direct from the sun. We consider the sunlight during our experiments to be near $100 \%$ diffused and the light from the supplemental light to be direct to a high degree (greater than 60\%), although it is difficult to measure and relate to how the plants sense the light.

Differences in the assimilation of plants grown in diffused versus direct light conditions might relate to the structure of the leaf as studied by several (Brodersen and Vogelmann, 2007; Brodersen et al., 2008; DeLucia et al., 1996; Vogelmann et al., 1996; Vogelmann and Martin, 1993). We did not look at the leaf anatomy, but this might be relevant for a clear explanation why a difference in the $\mathrm{A} / \mathrm{CLA}$ per $P P F$ is seen depending on the light composition. Our result could be the result of a combination of both quality and diffuseness and further studies are needed to uncover this.

We consider factors like the natural light intensity, plant age in combination with the diffuseness of light, and the measurements of injected $\mathrm{CO}_{2}$ to the system to be of high importance for the results.

Although we normalized all assimilation data to the CLA estimations, we do not know from experiment $\mathrm{T}_{\text {Change }}$ whether the differences in $\mathrm{CO}_{2}$ uptake were caused by the weekly differences in the sunlight, plant age, or by the supplemental light treatment. Not being able to separate these factors in the experimental setup is why we made two simultaneously running experiments.

In experiment $\mathrm{T}_{\text {Keep }}$, the plants followed their respective treatments but were moved among the four chambers to reduce differences between the chambers. The results showed that the chamber effects (C) were greater than the treatment effects $(\mathrm{T})$ and it resulted in $\mathrm{T}$ and $\mathrm{C}$ interaction effects $(\mathrm{T} \times \mathrm{C}$; $\mathrm{F}=2.66, P=0.023$ ) that could not be eliminated.

In experiment $\mathrm{T}_{\text {Keep }}$, we introduced the errors of different chambers. Because we tested four treatments in four chambers at the same time in experiment $\mathrm{T}_{\text {Keep }}$, we cannot detect whether one treatment is better than the other or it all depends on the chamber used.

Estimates of A/CLA for chamber 2 were generally higher than for chambers 1,3 , and 4 and therefore we cannot argue for any of the treatments being more productive in terms of greater A/CLA. Moreover, we did find a difference in the A/CLA depending on the plant age or the light at the given time period in experiment $\mathrm{T}_{\text {Change, }}$ which contributes to a less transparent result of experiment $\mathrm{T}_{\text {Keep }}$. However, we consider the chambers to be so alike that the relative low effect of $\mathrm{T}$ compared with the effect of $\mathrm{C}$ in experiment $\mathrm{T}_{\text {Keep }}$ indicates that the treatments are sufficiently similar such that the effect can be ignored at a production level.

Daylight climate chambers are influenced by the sunlight and the large variations in the outdoor radiation makes it difficult to compare assimilation during $1 \mathrm{~d}$ (or week) with assimilation during another. Moreover, the plants are growing so that the dry matter increases with time. This makes it impossible to make true repetitions of an experiment, but with the influence of natural sunlight, we mimic a real growing situation of commercial greenhouse production.

The plant metabolism is regulated by photosynthesis and redox signals synchronized by the daily light-to-dark and other environmental cycles. Redox control, in addition to specific photoreceptors like phytochromes and cryptochromes, integrates rhythmic gene expression in chloroplasts, mitochondria, and the nucleus (Albrechtová et al., 2006). The interruption of the daily rhythm of the light-to-dark cycle might change or reset circadian rhythms in plants influencing photosynthesis (Dodd et al., 2005), but in this study of the canopy photosynthesis, we were not able to detect any disadvantage, e.g., less A/CLA or growth in the T23-04 with light interrupting the night.

The highly variable electricity prices (varying on hourly basis) are not uncommon in Denmark and other northern European countries because of increased use of alternative energy sources like wind power. The analysis of the electricity prices showed that the most expensive fixed 5-h period of the day with supplemental light tested was more than $66 \%$ more expensive than the cheapest period during the time of the experiment. However, by daily regulations of the hours with supplemental light by avoiding supplemental light during the expensive hours and applying light during the less expensive ones will decrease costs even more.

We obtained identical climate and light integrals among the treatments and no significant differences could be found among the treatments in terms of growth or DW. Results of growth and DW suggest that specific timing of supplementary light to achieve higher net photosynthesis is not relevant for future climate control strategies during low-light periods when supplemental light is usually used. No one treatment was found to be superior in terms of greater estimated A/CLA in experiment $\mathrm{T}_{\text {Keep }}$. However, experiment $\mathrm{T}_{\text {Change }}$ resulted in less $\mathrm{A} /$ CLA in treatment TCh10-15 (Week 1), which is assumed to be caused either by low net assimilation in the earlier growth stage of the plant or by the longer duration of darkness and loss of $\mathrm{CO}_{2}$ through dark respiration caused by the treatment. Our results and the highly variable hourly electricity prices considered imply that a specific timing of 
supplementary light to achieve higher net photosynthesis is irrelevant in practical. Supplemental light can be controlled in accordance with the hourly electricity prices to economic advantage during the dark and low-light periods during winter. Under the experimental conditions described, we found this to be true for chrysanthemum in a vegetative stage, but this might not be true for all plant species.

\section{Literature Cited}

Albrechtová, J.T.P., M. Vervliet-Scheebaum, J. Normann, J. Veit, and E. Wagner. 2006. Metabolic control of transcriptional-translational control loops (TTCL) by circadian oscillations in the redox- and phosphorylation state of cells. Biol. Rhythm Res. 37:381-389.

Brodersen, C.R. and T.C. Vogelmann. 2007. Do epidermal lens cells facilitate the absorptance of diffuse light? Amer. J. Bot. 94:1061-1066.

Brodersen, C.R., T.C. Vogelmann, W.E. Williams, and H.L. Gorton. 2008. A new paradigm in leaf-level photosynthesis: Direct and diffuse lights are not equal. Plant Cell Environ. 31:159-164.

DeLucia, E.H., K. Nelson, T.C. Vogelmann, and W.K. Smith. 1996. Contribution of intercellular reflectance to photosynthesis in shade leaves. Plant Cell Environ. 19:159-170.

Dodd, A.N., N. Salathia, A. Hall, E. Kevei, R. Toth, F. Nagy, J.M. Hibberd, A.J. Millar, and A.A.R. Webb. 2005. Plant circadian clocks increase photosynthesis, growth, survival, and competitive advantage. Science 309:630-633.
Gartnerirådgivningen/AgroTech. 2008. Brancheaftale for gartnerierhvervet 2006 til 2008: Årsrapport for 2007. p. 1-16.

Gundersen, H.J.G. 2002. The smooth fractionator. J. of Microscopy-Oxford 207:191-210.

Hollinger, D.Y., F.M. Kelliher, J.N. Byers, J.E. Hunt, T.M. Mcseveny, and P.L. Weir. 1994. Carbon-dioxide exchange between an undisturbed old-growth temperate forest and the atmosphere. Ecology 75:134-150.

Hotta, C.T., M.J. Gardner, K.E. Hubbard, S.J. Baek, N. Dalchau, D. Suhita, A.N. Dodd, and A.A.R. Webb. 2007. Modulation of environmental responses of plants by circadian clocks. Plant Cell Environ. 30:333-349.

Jensen, L.T., E. Rosenqvist, and J.M. Aaslyng. 2006. A daylight climate chamber for testing greenhouse climate control strategies and calculating canopy carbon dioxide exchange. HortTechnology 16:191-198.

Møllenberg, S. 2003. Gartneriregnskabsstatistik 2002: Materialeudvælgelse og definitioner. Fødevareøkonomisk Institut, Rolighedsvej 25, 1958 Frederiksberg C., Denmark.

Møllenberg, S. 2007. Gartneriregnskabsstatistik 2006: Materialeudvælgelse og definitioner. Fødevareøkonomisk Institut, Rolighedsvej 25, 1958 Frederiksberg C., Denmark.

Nemali, K.S. and M.W. van Iersel. 2004. Light effects on wax begonia: Photosynthesis, growth respiration, maintenance respiration, and carbon use efficiency. J. Amer. Soc. Hort. Sci. 129:416-424.

Norman, J.M., E.E. Miller, and C.B. Tanner. 1971. Light intensity and sunfleck-size distributions in plant canopies. Agron. J. 63:743-748.
Roderick, M.L., G.D. Farquhar, S.L. Berry, and I.R. Noble. 2001. On the direct effect of clouds and atmospheric particles on the productivity and structure of vegetation. Oecologia 129:21-30.

Rosenqvist, E. 2001. Light acclimation maintains the redox state of the PSII electron acceptor $\mathrm{Q}(2)$ within a narrow range over a broad range of light intensities. Photosynth. Res. 70:299310.

Thornley, J.H.M. 2002. Instantaneous canopy photosynthesis: Analytical expressions for sun and shade leaves based on exponential light decay down the canopy and an acclimated nonrectangular hyperbola for leaf photosynthesis. Ann. Bot. (Lond.) 89:451-458.

Tibbitts, T.W., D.A. McSparron, and D.T. Krizek. 1986. Spectral effects on the use of photon flux sensors for measurement of photosynthetic photon flux in controlled environments. Biotronics 15:31-36.

Vogelmann, T.C., J.F. Bornman, and D.J. Yates. 1996. Focusing of light by leaf epidermal cells. Physiol. Plant. 98:43-56.

Vogelmann, T.C. and G. Martin. 1993. The functional-significance of palisade tissue: Penetration of directional versus diffuse light. Plant Cell Environ. 16:65-72.

Wulfsohn, D., M. Sciortino, J.M. Aaslyng, and M. García-Fiñana. 2009. Non-destructive, stereological estimation of canopy surface area. Biometrics. DOI: 10.1111/j.1541-0420.2009.01237.x

Xu, Q.Z., B.R. Huang, and Z.L. Wang. 2004. Effects of extended daylength on shoot growth and carbohydrate metabolism for creeping bentgrass exposed to heat stress. J. Amer. Soc. Hort. Sci. 129:193-197. 